BRIEF SUMMARY of PRESCRIBING INFORMATION

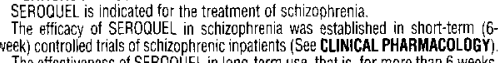

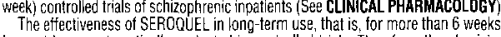
has not beer systematicalliy evaluated in controlled trials. Therefore, the physician
who elects to use SEROOuEL tor extended periods should periodically re-valuate the Iong-term usefulness of the drug for the individual patient.
CONTRANDICATIONS

medication or any of its ingrediedints.
WARNINGS

WARNINGS
Neuroleptic Malignant Syndrome: (UMS) A potentially fatal symptom complex

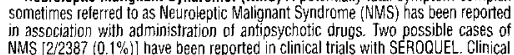
man ifestations of NMIS are hyperpyrexia, muscle rigicity, altered mental status, and evidence of autonomic in stability (irregular pulse or blood pressure, tachycardia,
diaphoressis. and cardiac dysthythmia). Addititional signs may include eleyaded creatine phosphokinase, myoglobinuria ichabdomyolysiss and acute renal tailure. The diag
nostic evaluation of patients with this synorome is complicated. Ir: arriving at a diannosis, it is important to exclude cases where the clinical presentation includes
both serious medical illness (e.g. preumonia, systemic infection, etc.) and untreater or inadequateley treated extrapyramidal signs and symptoms (EPS). Other important heat stroke. drug fever and primary central nervous system (CNS) pathology The
management of NMS should include: 1 immediate discontinuation of antipsychotic druass and other drugs rot essential to concurrent therapy: 2 ) intensive symptomatic
treatment and medical monitoring; and 3 ) treatment of any concomitant serious medical problems for which specilic treatments are availabie. There is no general

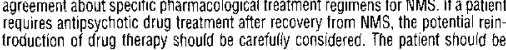
caratully monitored since recurrences of NMS have been reportted. Tardive
Dyskinesia: A syndrome of potentially irreversible involuntary, dyskinetic move-
ments may develop in patients treated with antipsychotic drugs. Although the prevalence of the syndrome appears to be highest among the ederly, especially elderly worrent, it is impossible to rely upon prevalence estimates to predict, at the
inseption of ant psychotic treatment, which patients are tikely to develop the syn

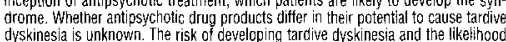
dyskinesla is sumnown.
that it will become irreversible are believed to increase as the duration of treatment
and the total cumulative dose of antipsychotic drugs administered to the patient increase. However, the syndrome can develoc, although much less commonly, atter
relatively brief treatment periods at low doses. There is no known treatment to established cases of tarcive dyskinesia, although the syndrome may remit, partially
or completely, if antipsychotic treatriment is withdirawn. Antipsychotic treatrientit,

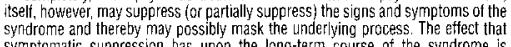
symptomatic suppression has upon the long-term course of the syndrome is
unknown. Given these considerations, SEROCQUEL should be prescribed in a manner
that is mast likely to minimize the occurrence of tard lye dyskinessia. Chronic antipsychotic treatment should generally be reserved tor patients who appear to suffer from
a chronic illness that (1) is known to respond to antipsychotic drugs and (2) for a chrorici illness that (1) is known to respond to antipsychotic drugs, and (2) for
whom alternative, equally effective, but potentially less harmitul treatments are not
ayailatle or appropriate in patients who jo require chronic treatment the smallest avaliable or approprlate. In patients who do require chronic treatment, the smallest
dose and the shortest duration of treatment producing a satistactory cinical

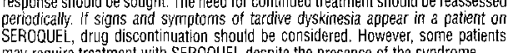
may require treatment with SEROOUEL desp te the presence of the syndrome.
PRECAUTOONS: General Orthosiatic Hypolension: SEROOUEL may ind uce orthostatic hypotension asso-
iated with dizziness, tachycardia and, in some patients, syncope, especially during

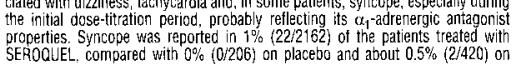

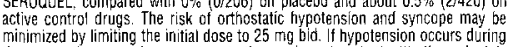
titration to the target dose, a return to the previous dose in the titration schedule
is appropriate. SEROQuUEL should be used with particular caution in palients with
knowsn cardiovascular disease inistory of myocardiat infarction or ischemic heart disease, heart failure or concuction abnormalities), cerebrovascular disease or con-
ditions which would predispose patients to hypotension (dehydration, hypovolemia and treatment with antitiypertensive rredications). Cataracts: The development of studies (see Animal Toxicology). Lens changes have also been observed in

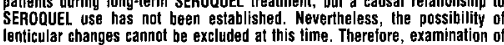
the lens by methods adequate to detect cataract formation, such as slit lamp exam or other appropriately sensitive methods, is recommended at initiation of treatment or shorty hereatiger, ant al 6 month intervals during chronic treatment.
Seizures: During clinical trials, seizures occurred in $0.8 \%$ (18/2387) of patients

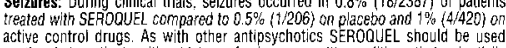

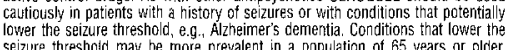
Seizure threshold may be more prevalent in a population of 65 years or older.
Hypothyroidism: Clinical trials with SEROQUEL demonstrated a dose-related

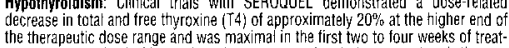

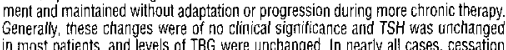
of SER COUEL L treatment was associated with a reversal of the effects on total and free T4, irrespective of the duration of treatment. About $0.4 \%$ (10/2386) of
SEROQUEL patients dio experience TSH increases. Six of the patients with TSH increases needed replacement thy thid treatment. Cholesterol and Triglyceride
Elevations: In a pool of 3 - to 6 -week placebo-controlled trals, SEFOCUE-treated patients had increases from baseline in cholestercol and triglyceride of $11 \%$ and
$17 \%$, respectively, compared to slight decreases for placebo patients. These
channges were only weakly related to the increases in weight osserved in SEROQUEL-

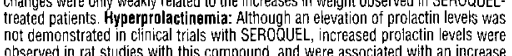
in mammary gland neoplasia in rats (see Carcinogenenesis). Tissue culture experit-
ments indicate that approximatelly one-third of human breast cancers are prolastin dependent in vitro a a factor of of potential importance if the prescription of these drugs
is contemp lated in a patient with previousiy detected breast cancer. Although is contemplated in a patient with previously detected breast cancer. Although
disturbances such as galactorthea, amenorrhea, gynecomastia, and impotence
have been reported with protactin-elevating compounds the clinicical significicance of elevated serum prolactin leveres is uninkoum tor most tatients. Neither clinical studies chronic administration of this class of drugs and tumorigenesis in humans, the
available evidence is considered too timited to be conclusive at this time. Transaminase Elevalions: Asyrnptomatic, transient and reversible elevations in
serum transaminases (primarily ALT) have been reported. The proportions of
patients with transaminase elevations of $>3$ : 3 imes the uoper limits of the riorma

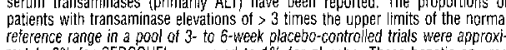

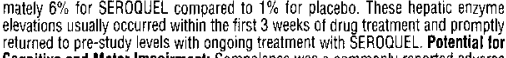

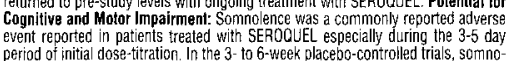
period of initial dose-titration. In the 3- to 6-week place bo-controlled trials, Somno-

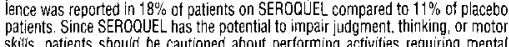
alertness, such as operating a motor vehicle including automobiles; or operating

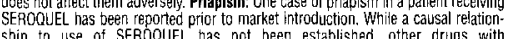
atpha-adrenergic biocking effects have been reported to induce priapism, and it is possible that $S E R O Q D U F L$ may share this capacity. Severe priapism may require
surgical intervention. Body Temperature Regulation: Although not reborted with SEROQUUE, disrlution of the hody's ability to reduce core body temperatura has
been attributed to antipsychotic agents. Appropriate care is advised when, prescribing to an elevation in core body temperature, e.g. exercising strenuously, expossure to
extreme heat, receiving concomitant medication with anticholinergic activity. of
being subject to dehydration. Dysphagia: Esoohageal dysmotility and aspiration
SEROQUEL (quetiapine fumarate) Tablets

have been associated with antipsychotic drug use. Aspiration pneumonia is a common
cause of morbidity and mortality in elderly patients, in particular those with

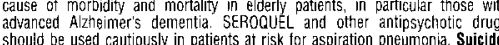
The possibitity of a suicide attempt is intherent in schizophrenia and close supervision
of high risk patients should accornpany drug therapy. Prescriptions for SEFOOUf should be witten for the smallest quantity of tablets consistent with good patient
management in order to reduce the risk of overcose. Use in Patients with
Concomitant Illness: Clinical experience with SEROQuUEL in patients with certain concomitant systemic illnesses is limited. SEROQUEL has not been evaluatad ar
used to any aporeciable extent in patients with a recent history of myocardial intarstion or unstable heart disease. Patents with these diagnoses were excluded from
premarketing linical studies. Bectause of the risk of orthostatic yypotension with SEROQUEL, caution should be observed in carciac patients see Orthostatic
Hypotension). Intormation for Patients: Physicians are advised to discuss th

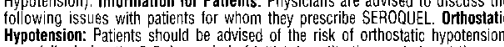
especially during the $3-5$ day period of initial dose titration, and also at times of
re-in titating greatment or incereases in dose. Interterence witit Cognnitive and Motor with SEROQUEL treatment, patients should be advised of the risk of somnolence.
especially during the $3-5$ day period of initial cose titration. Patients should be
cautioned about performing any activity requiring mental aleriness, such as operating

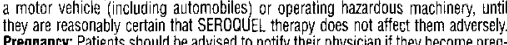

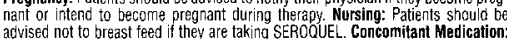
advised not to breast feed if they are taking $S E R O O U E L$. Coneomitant Medication
As with other medications, patients shculd be advised to notify their physicians

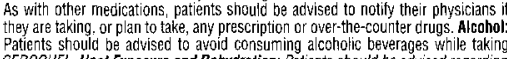
$S E R O O U E L$. Heai Exposure and Oehyoration: Patients should te advised regarcing appropriate care in avoiding overheating and denydration. Laboratery Tesis: SEROQUEL in combination with other drugs have not been extensively evaluated in
systematic studies. Given the primary CHS effects of SERCQUEL, caution should b used when it is taken in combination with other centrally acting drugs. SERCQUE
potentiated the cognitive and motor effects of alcohol in a clininal trial in subjects with selected psychotic discrders, and alcoholic beverages should be avoided whil
taking SEROOLEL. Because of its potential for inducing hypotersion, SEROQUE

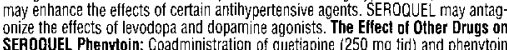

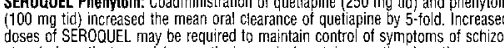
phrenia in patients receiving cuetiapine and phenytoin, or other hepatic enzymm
inducers (e.g., carbamazepine, barbiturates, rifampin, glucocorticoids). Gaultion should be taken if phenytoin is ivithdrawn and replaced with a non-inducer (e.g

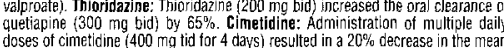
doses of cimetidine (400 mig tid for 4 days) resulted in a $20 \%$ decrease in the mean
oral clearance of quetiapine $150 \mathrm{mg}$ tid). Dosage adjustment for quetiapine is no

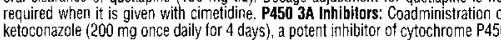

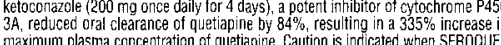

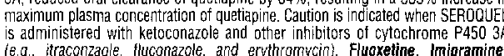

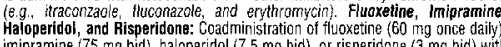

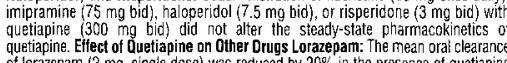
of lorazepam (2 $\mathrm{mg}$, single dosel was reduced by $20 \%$ in the presence of quetiapine
adminisistered as $250 \mathrm{mg}$ tid dosing. Lithium: Concomitant administration of quetiapine (250 $\mathrm{mg}$ tid) with ithium had no effect. on any of the steady-stab coses up to $750 \mathrm{mg} / \mathrm{day}$ (on a tid schedule) of quetiapine to subjects with selected
psychotic disorders had no clinically relevant effect on the clearance of antipyrine o

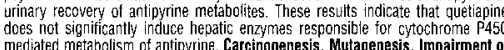
Fertility Carcinogenesis: Carcinogencicity studies were conducted in $557 \mathrm{BL}$ mic 250 , and $750 \mathrm{mg} / \mathrm{kg}$ and to rats by gavace at doses of 25,75 , and $250 \mathrm{mg} / \mathrm{kg}$ to
two years. These doses are equivalent to $0.1,0.5,1.5$, and 4.5 times the maximum human dose ( $800 \mathrm{mg} / \mathrm{day}$ on a $\mathrm{mg} / \mathrm{m}^{2}$ basis (mice) or $0.3,0.9$ and 3.0 times th

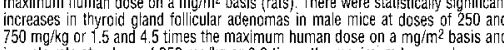
in male rats at a dose of $250 \mathrm{mg} / \mathrm{kg}$ or 3.0 times the maximum human dose on
mg/m? tasis. Mammary gland adenocoarcinomas were staristically significantly
increased in temale rats at all doses tested $(25,75$, and $250 \mathrm{mg} / \mathrm{kg}$ or $0.3,0.9$, and

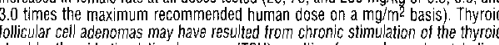
gland by thyroid stimulating hormone eTSH) resulting from enhanced metabolism and ciearance of thyroxine by rodent liver. Changes in TSH, thyroxine, and thyroxine
clearance consistent with this mechanism weres observed in subchronic toxicity
studidies in rat and mouse and in a 1 -year toxicity study in rat, however, the results of these studies were rot definitive. The relevance of the increases in thyrroid follicula
cell adenomas to human risk, through whatever mechanism, is unknown Antipsychotic drugs have beern shown to chronically elevate prolactin levels rodents. Serum measurements in a 1 -yr toxicity study showed that quetiapine
increased median serum proiactin levels a maximum of 32 -and 13 -fotd in male and female rats, respectively. Increases in mammary neoplasms have been found in to be prolactin-mediated. The relevance of this increased insidence of prolactin-

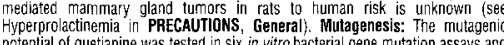

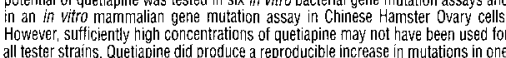

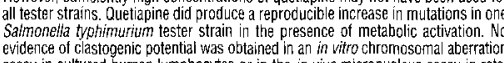
assay in cultured humen lymphocytes or in the in vivo micronucleus assay in rats. Impairment of Fertility: Quetiapine decreased mating and fertility in male Sprague-
Dawley rats at oral doses of 50 and 150 mgg/kg or 0.6 and 1.8 times the maximum

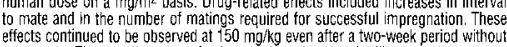
trealment. The no-effect dose for impaired maling and ferility in male rats was
25 mg.kg. or 0.3 times the maximum human dose on a mo/m² basis. Quetiapine adversely affected mating and fertility in temate Sprague-Dawley rats at an oral dose
of 50 mgikg, or 0.6 times the maximum human dose on a mogm ${ }^{2}$ basis. Orug-related

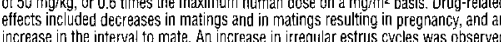
at doses of 10 and 50 mg/kg, or 0.1 and 0.6 times the maximum humman dose on
$\mathrm{mg}^{\prime} \mathrm{m}^{2}$ basis. The no effect dose in female rats was $1 \mathrm{mg} / \mathrm{kg}$, or 0.01 times th

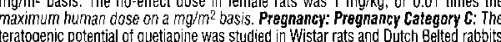

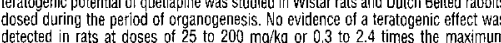
human dose on a mg// $\mathrm{m}^{2}$ basis or in rabbits at 25 to $100 \mathrm{mg} / \mathrm{kg}$ or or 0.6 to 2.4 times the maximum human dose on a $\mathrm{mg}^{\prime 2} \mathrm{~m}^{2}$ basis. There was, however, evidence of
embryoffetal toxicity. Delays in skelatal ossitication were detected in rat fetuses a

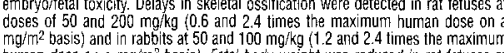
hurilan dose on a mg/m² basis). Fatal body weight was reduced in rat fetuses a
$200 \mathrm{~m}$ mokg and rabbit fetuses at $100 \mathrm{mog} / \mathrm{kg}$ (2.4 times the maximum human dose on a mg/me basis for both species. There was an increased incidence of a minor
soft tissue anomaly (carpal/tarsal flexurei in rabbit tetuses at a dose of $100 \mathrm{mg} / \mathrm{kg}$ (2.4 times the maximum human dose on a mg/m² basiss.). Evidence of maternal tox-
icity (i.e. decreases in body weight gain and/or death was otserved tat the high

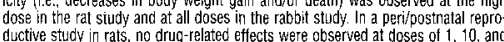
$20 \mathrm{mg} / \mathrm{kg}$ or $0.01,0.12$, and 0.24 times the maximum human dose on a mg/m2

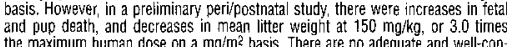
trolled studies in pregnant women and puetiapine should be used during pregnancy
only if the potential benefit justifies the potential risk to the fetus. Labor and
Defivery: The effect of SEROQUUEL on labor and delivery in humans is unknown
SEROQUEL (quetiapine fumarate) Tablets

Nursing Mothers: SEROQUEL was excreted in milk of treated animals during lactawom. It is not known if SEROQUEL is excreted in human milk. It is recommended that

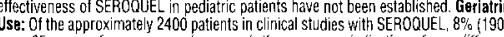
were 65 years of age or Over. In general, there was no incícation of any different presence of factors that might decrease pharmacokinetic clearance, incereaso the pharshould lead to consideration of a lower starting dose, slower titration, and carefu

\section{YOUnger patients.} Adverse Events Occurring at an Incidence of $1 \%$ or More Among SEROQUEL
Treated Patisnts in Short: Term. Placebo-Controlled Trials: The most comminonly greater) and observed at a rate on SEROOUEL at least twice that of placebo were of $1 \%$ or more, and were at least as treauent among SEROCUEL treated patients. - to 6-week placebo-controlled trials.
Body as a Whole: Headache, Asthenia, Abdominal pain, Back pain. Fever, Nervous
System: Somnolence. Dizziness: Digestiva System: Constipation. Dry Mouth. System: Somnolence, Dizziness: Digestive System: Constipation Dry Mouth.
Dyspepsia: Cardiovastudar System: Postural hypotension, Tachycard la: Matabolit Dyspepsla: Cardiovastular System: Postural hypotension, Tachycard a: Metabolic
and Nutritional Disorders: Weight gain; Skin and Appendages: Rash, Respiratory Sysiem: Rininitis' Special Senses: Ear pain
IEvents for which the SEROOUEL incidence was equal to or less than placetobo are not listed in the table, but included the following pain, infection, chess: pain, hostlitity

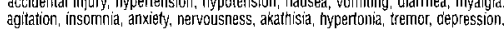
paresthesia. pharangititis, dry skin, amblyopia and uynary tract infection.
rxplorations for interactions on the basis of gender. age, and race did not reveal any

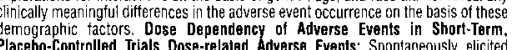

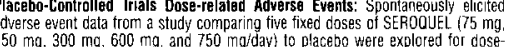

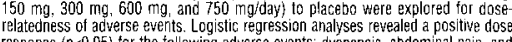

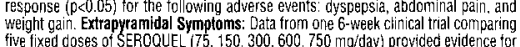
the lack of treatment-ernergent extrapyraninidal symptoms (EPS) and dose-relatedness
to $E P S$ associated with SEROQUEL treatment. Three methods were used to measure EPS: (1) Simpson-Angus total score imean change from baseline) which evaluates
parkinsonism and akathisia, (2) incidence of spontaneoss complaints of EPS

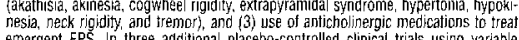
Emergent EPS. In three add titional placebo-controlled clinical trials using variable
doses of SEROQUEL, there were no differences between the SERCOUEL and placebo treatment groups in the incidence of EPS, as assessed by Simpson-Angus total
scores, spontaneous complaints of EPS and the use of concomitant anticholinergic

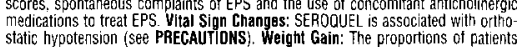

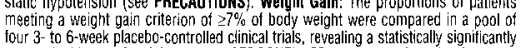
greater incidence of weight gain tor SEROOUEL (23\%) compared to placebo i6\% 6 .

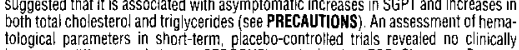

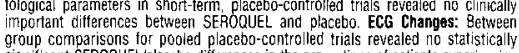
potentially important chacebo differences in the proportions of patients experiencing potentially important changes in ECG parameters, including OT, QTC, and PR intervals,

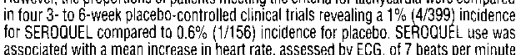
associated with a mean increase in heart rate, assessed by ECG, of 7 beats per minute slight tendency to tachycardia may be related to SEROQUEL's potential for inducing
orthostatic changes (See PRECAUTIONS). Other Adverse Events Observed During the Pre-Marketing Evaluation of SEROQUEL: Following is a list of COSTART termins AOVERSE REACT OONS section reported by patients treated with SEROOUEL at multiple coses $\geq 75$ mg;day during any phase of a trial within the premarketing database of
approximately 2200 patients. All reported events are included except those alseady
listerc in Tabe 1 or elsewhere in labeling. those events for which a drug cause was remote, and those event terms which were so general as to be uninformative. It is
important to emphasize that, although the events reported occurred during treatment by body system and listed in order of decreasing frequency accorcing to the tollowing
definitions: frequent adverse events are those occurring in at least $1 / 100$ patients (only those not aleready listed in the tabulated results from placebc-controlled trials appear in this listing): infrequent adverse events are those occurring in $1 / 100$ to
$1 / 1000$ patientsts; rae events are those occuring in fewer than $1 / 1000$ patients. dyskinesia, thinking abnormal, tardive dyskinesia, yertigo, involuntary movernents,
confusion, amnesia, psychosis, hallucinations, hyperkinesia, libido increased ${ }^{*}$, urinary retention, incoordination, paranoid reaction, abnormal gait, myocionus, de usions,
manic reaction, apathy, ataxia, depersonalization, stupor, bruxism, catatonic reaction,

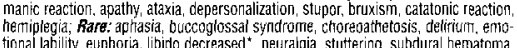

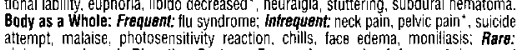

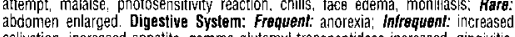

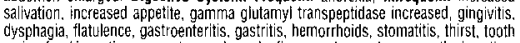

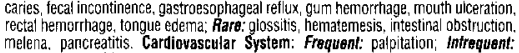

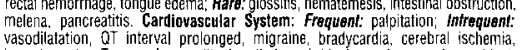

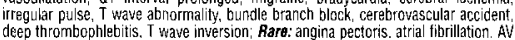
block first degree, congestive heart falure, ST elevated, thrombophlebitis, T wave flat-
tening, ST abnormality, increased GRS duration. Resplratory System: Frequent: pharyngitis, rhinitis, cough increased, dyspnea; Infrequent: pneummonia, epistaxis,

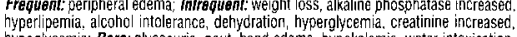

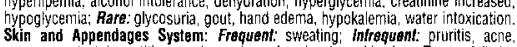

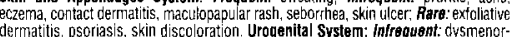

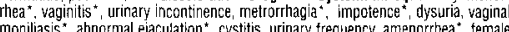

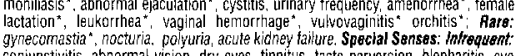
conjunctivitis, abnormal vision, dry eyes, tinnitus, taste perversion, blepharitis, eye
pain, Rare: abnormality of accornmodation, deathess, glaucoma. Musculoskeletal System: Infrequent: pathological tracture myasthenia, twitching, arthralgiac, arthritis,

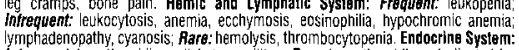

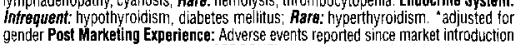

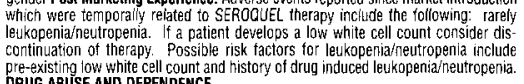
DFUG ABUSE AND DEPENDENCE
Controlled Substance Class: SEROQUEL is not a controlled substance. 


\section{Editorial Questionnaire}

Your comments are important to us. This form provides you with the opportunity to express your opinions. Our goal is to make CNS Spectrums your source for practical and clinical neuropsychiatric information. By filling out this Questionnaire, you enable us to incorporate your views about our editorial content in future issues. Please fill out this form in its entirety. Thank you.

Name (please print)

Address

City $\quad$ State Zip Code

E-mail

Specialty

Signature

Date

Fax this form to 212-328-0600. Or mail it to: CNS SPECTRUMS, MBL Communications, Inc., 333 Hudson Street, 7th Floor, New York, NY 10013

1. On a scale of 1 to 5 ( $1=$ Poor, $5=$ Excellent), please indicate your level of interest and/or satisfaction with the editorial content in this issue.

\section{Review Articles}

Genetically Altered Mice in the Study of Neuropsychiatry

$\square 1 \quad \square 2 \quad \square 3 \quad \square 4 \quad \square 5$

\section{Departments}

Clinical Updates in Neuropsychiatry
$\square 1 \square 2$
$\square 3$
$\square 4$

From the Editor's Desk

$\square 1 \quad \square 2 \quad \square 3 \quad \square 4 \quad \square 5$

CME

$\square 1 \quad \square 2 \quad \square 3 \quad \square 4 \quad \square 5$

The Neurology of Behavior

$\square 1 \quad \square 2 \quad \square 3 \quad \square 4 \quad \square 5$

2. Which areas of neuropsychiatry would you like us to cover in the future?

\section{CME Accredited CNS Roundtable Monographs and CD-ROMs}

$\square$ The Use of Lithium in Bipolar Disorder

$\square$ Part 1: Recognizing Comorbidities Associated With Bipolar Disorder

$\square$ Part 2: Remission-Oriented Treatment Considerations of Bipolar Disorder

$\square$ Part 3: Optimizing Therapeutic Options in the Treatment of Bipolar Disorder

$\square$ Recognizing Comorbidities Associated With ADHD
3. Please describe your reading pattern for this issue:

$\square$ Read cover to cover

$\square$ Skimmed table of contents

$\square$ Read select items of interest

$\square$ Skimmed text

$\square$ Did not read

4. On a scale of 1 to 5 ( $1=$ Incomplete, $5=$ Comprehensive), how would you describe the depth of coverage for this issue?

$\square 1 \square 2 \quad \square 3 \quad \square 4 \quad \square 5$

5. Any other comments about CNS Spectrums' editorial content, design, or overall, overall usefulness?

6. Please indicate your title:

\section{Psychiatrist}

$\square$ Neurologist 
Your comments are important to us. This form provides you with the opportunity to express your opinions. Our goal is to make CNS Spectrums your source for practical and clinical neuropsychiatric information. By filling out this Questionnaire, you enable us to incorporate your views about our editorial content in future issues. Please fill out this form in its entirety. Thank you.

Name (please print)

Address

\begin{tabular}{lll}
\hline City & State & Zip Code \\
\hline E-mail & Specialty
\end{tabular}

Fax this form to 212-328-0600. Or mail it to: CNS SPECTRUMS, MBL Communications, Inc., 333 Hudson Street, 7th Floor, New York, NY 10013

1. On a scale of 1 to 5 (1=Poor, $5=$ Excellent), please indicate your level of interest and/or satisfaction with the editorial content in this issue.

\section{Review Articles}

Genetically Altered Mice in the Study of Neuropsychiatry

$$
\square 1 \quad \square 2 \quad \square 3 \quad \square 4 \quad \square 5
$$

\section{Departments}

Clinical Updates in Neuropsychiatry

$$
\square 1 \quad \square 2 \quad \square 3 \quad \square 4 \quad \square 5
$$

From the Editor's Desk

$\square 1 \quad \square 2 \quad \square 3 \quad \square 4 \quad \square 5$

CME

$\square 1 \quad \square 2 \quad \square 3 \quad \square 4 \quad \square 5$

The Neurology of Behavior

$\square 1 \square 2 \square 3 \quad \square 4 \quad \square 5$

2. Which areas of neuropsychiatry would you like us to cover in the future?

\footnotetext{
CME Accredited CNS Roundtable Monographs and CD-ROMs

$\square$ The Use of Lithium in Bipolar Disorder

$\square$ Part 1: Recognizing Comorbidities Associated With Bipolar Disorder

$\square$ Part 2: Remission-Oriented Treatment Considerations of Bipolar Disorder

$\square$ Part 3: Optimizing Therapeutic Options in the Treatment of Bipolar Disorder

$\square$ Recognizing Comorbidities Associated With ADHD
}

3. Please describe your reading pattern for this issue:

$\square$ Read cover to cover

$\square$ Skimmed table of contents

$\square$ Read select items of interest

$\square$ Skimmed text

$\square$ Did not read

4. On a scale of 1 to 5 ( $1=$ Incomplete, $5=$ Comprehensive), how would you describe the depth of coverage for this issue?

$\square 1 \quad \square 2 . \square 3 \quad \square 4 \quad \square 5$

5. Any other comments about CNS Spectrums' editorial content, design, or overall, overall usefulness?

6. Please indicate your title:

$\square$ Psychiatrist

$\square$ Neurologist

\section{Clinical Pocket Reference Guides}

$\square$ The 2003 Black Book of Psychotropic Dosing and Monitoring

$\square$ The Diagnostic and Therapeutic Guide to Sleep Disorders

$\square$ The Effects of Antidepressants on Human Sexuality

$\square$ Dosing and Monitoring Guidelines: Mood Disorders

$\square$ The Side-Effect Profiles of Antipsychotic Medications

$\square$ The Black Book of Geriatric Psychopharmacology 
